\title{
Erratum to: Crystal Structure and Thermal Decomposition of Square Planar Ni (II) Complexes with ONS Type Ligands
}

\author{
Sefa Durmuş • Cengiz Arıcı • Ertan Şahin • \\ Ümit Ergun · Orhan Atakol
}

Published online: 26 November 2010

(C) Springer Science+Business Media, LLC 2010

Erratum to: J Chem Crystallogr (2010) 40:788-793

DOI 10.1007/s10870-010-9738-2

The affiliation of Dr. Sefa Durmuş has been published incorrectly. The correct address for Assoc. Prof. Dr. Sefa Durmuş is listed below.

The online version of the original article can be found under doi:10.1007/s10870-010-9738-2.

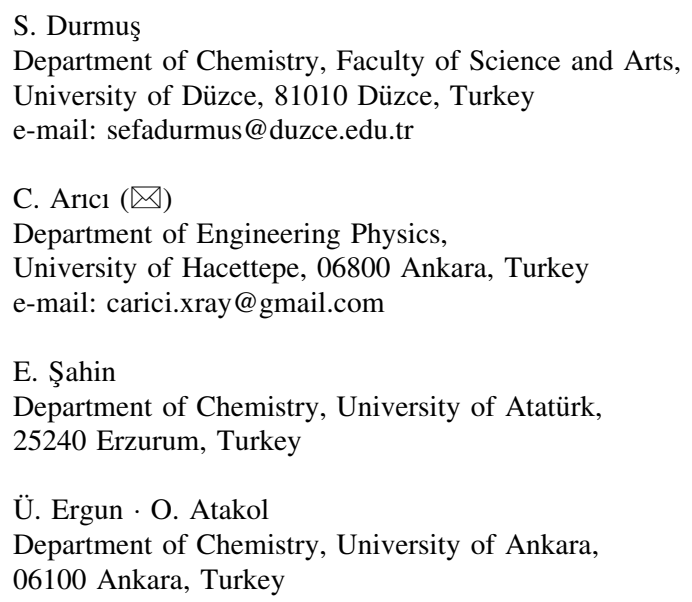

